\title{
Using the Relationship Between Market Economy and Ethics in Enhancing Medical Ethics to Health Care Staff in Vietnam Nowadays
}

\author{
Chu Tuan $\mathrm{Anh}^{1} \&$ Do Thi Nhuong ${ }^{1}$ \\ ${ }^{1}$ Thai Nguyen University of Medicine and Pharmacy, Thai Nguyen, Vietnam \\ Correspondence: Chu Tuan Anh, Thai Nguyen University of Medicine and Pharmacy, No 284, Luong Ngoc \\ Quyen street, Thai Nguyen, Thai Nguyen, Vietnam.
}

Received: August 5, 2018

Accepted: August 21, 2018

Online Published: August 22, 2018

doi:10.20849/ajsss.v3i3.455

URL: https://doi.org/10.20849/ajsss.v3i3.455

\begin{abstract}
Over the past 30 years of renovation, the development of the socialist-oriented market economy has built up a team of good ethic and competent medical personnel who have devoted their lives to serving and caring health of people. However, the implementation and improvement of medical ethics in the past years has also been challenging such as harassment, negligence, hidden fees, low quality of examination and treatment, disease, etc., reducing the belief of the people for the noble duty "save life" of the medical staff. Therefore, enhancing medical ethics for health care workers is becoming more and more pressing.

This is a problematic situation where in the process of building a modern Vietnamese medicine that meets the requirements of development, must continue to study in order to have a scientific basis to set the direction and solution for further raising medical ethics for this team.
\end{abstract}

Keywords: ethics, raising medical ethics, health workers, market economy, socialist-oriented market economy

\section{Introduction}

Medical profession is a profession that exists in the combination of relationships with the goal of caring human health, for the well-being of all families, the future of the race, the prosperity of the whole society and of the whole population. The outstanding characteristic of this profession is careful, accurate, tolerant, sacrificed, emotional. There is no such thing as a medical profession, where a mistake, a small defect in the medical staff's profession, can cause bad consequences for the wrongdoer who has no chance of repairing it. Therefore, in addition to learning, training and upgrading specialized professional level, ethical training is an indispensable requirement in medical staff to meet the requirements of the industrial and modernization promotions in Vietnam currently.

The medical ethics of Vietnamese health care workers is expressed in the following norms: loyalty to the motherland, state and people, ideology life, ambition; persistence, honesty, principle, courage manifest in relationships with patients, colleagues, science and society. These moral norms are not invariant but are constantly changing with the development of society. Medical ethics of health care workers must be considered dialectically in relationships including economic benefits. Health care workers with good ethics are a direct factor in the development of the Vietnamese health sector in a sustainable manner.

\subsection{The Relationship Between Economics and Ethics in the Health Sector in Vietnam Nowadays}

\subsubsection{The Role of Socialist-Oriented Market Economy in Medical Ethics}

In the field of health, the market economy changes the nature of the settlement of the relationship between economics and morality, between the benefits of health workers and social benefits. Active participation in economic and social activities in a socialist-oriented market economy has opened up great possibilities for creativity in the health sector, it also facilitates the development of their moral qualities.

It is the transformation of the socialist-oriented market economy with its competition rules and its severely eradicated affecting all spheres of social life. Economic factors, economic conditions are more sufficient in a certain extent will be an important driving force in the development of the medical sector and medical ethics, expressed:

First, the economic factor ensures the planning guideline and policies of the Communist Party of Vietnam in terms of health clearly and ensure resources for implementation (from facilities, finance, medical staff training, etc.) 
Second, the economic factor guarantees the development of national plans, programs and strategies for the development of the health sector as a whole, as well as details in specific professional contents.

Third, the economic factor ensures a practical basis for the health sector to advise the Communist Party and the State of Vietnam on health policies; to raise the material and spiritual life of laborers of the heads of medical units.

Fourth, economic factors are guaranteed to contribute to the creation of ethical values and new professional ethical standards of health workers. On the contrary, these values and new ethical standards have been re-formed, contributing to the motivation of medical staff to fulfill their duties, indirectly forming healthy citizens who contribute to economic development.

\subsubsection{The Role of Medical Ethics to Health Workers in the Socialist-Oriented Market Economy}

Medical ethics are good qualities of Vietnamese health care workers. In the socialist-oriented market economy, medical ethics hold important positions in order for medical staff to fulfill their professional duties and deserve the people's trust on them. The role of medical ethics in the socialist-oriented market economy manifests itself in its functions. That is:

First, educational function.

Medical ethics is a form of professional ethics, and it is also a part of general moral consciousness so it also includes educational functions. The educational function of medical ethics contributes to the formation of norms, rules and basic ethical principles in the medical staff. Principles and norms which are properly understood will guide the behavior of health workers in their professional activities. Ethical education for health workers is the education of the qualities and fundamental virtues of the socialist-oriented market economy in Vietnam. It is virtue hard, thrifty, and impartial, being humble, honest, persevering, brave, etc.

\section{Second, cognitive function.}

In the socialist-oriented market economy in general and in the health sector in particular, there are interactive impacts between positive and negative, progress and backwardness, due to economic institutions and laws have not been fully established. Thus, besides the legal element, ethics is also an important tool for health workers to perceive and act in accordance with the norms and principles that society demands from them. Consequently, traditional medical ethical values, the principles of modern medical ethics, are perceived to help health workers distinguish the right, the wrong, the thing which need to be mended virtually. Cognitive function helps health workers perceive, train, adjust behavior in accordance with the interests of individuals, communities and society.

\section{Third, behavioral adjustment function.}

In medical examination and treatment, medical care for patients, medical ethics has the function of regulating the behavior of medical personnel according to the professional ethics standards prescribed by the profession. Health care workers have a clear mind; however sometimes the overload of work leads to unstable psychological symptoms that manifest into improper words, gestures which cause misunderstanding or lack of sympathy toward the sick and their family members.

On the other hand, with the function of regulating the behavior of medical ethics, medical personnel in all circumstances, different spaces have the capacity to manage flexibility and consistence in all situations of communication; behave with the patient, with colleagues showing the human nature and beauty of the medical staff. In addition, the function of regulating the behavior of medical ethics also allows health care workers to be immune to such bad habits as selfish behavior, corruption, lack of responsibility, lack of conscience, etc. due to the adverse side of the market economy which daily, hourly impact on them.

\section{Medical Ethical Situation of Health Workers in Vietnam, Review in the Relation Between Economics and Morality}

The Communist Party of Vietnam has initiated the renovation of the country since 1986. This innovative way has changed the management mechanism from the administrative mechanism, the focus and the subsidy to the market economy. This comprehensive reform of the Communist Party of Vietnam has blown a new life for the development of all aspects of society, including the health sector.

From the fact that the economic achievements of the socialist-oriented market economy in Vietnam affecting the health sector have contributed to the creation of moral values and new ethical standards of medical staff. On the contrary, these new values and ethical norms have been formed, contributing to the motivation for staff to fulfill their duties, indirectly forming healthy citizens who contribute to socio-economic development. The new ethical standards in medical staff are increasingly reinforced. Details: 


\subsection{In Relation to the Patient}

The relationship between the medical staff and the patient is a special relationship. In terms of the market economy, the relationship between the health worker and the patient is the relationship between the provider and the service user. Over thirty years of innovation has gradually formed in the medical staff working style and attitude, spirit of dedicated service, wholeheartedly, with the patient. Medical staffs perform professional activities for the purpose, great ideology has hidden in his bloodstream that is medical treatment to save lift. Over the past years, 13508 (Ministry of Health, 2017) public health facilities from the central to commune health stations and health workers have made efforts to overcome difficulties of facilitating, maintain activities of the unit in a positive way. They are health care workers who do not hesitate to sacrifice their youth to take care of the health of people in remote and island areas; those who are not afraid of dangerous transmission in the epidemic area; those who continuously try to produce good medicines with low price to meet with economic condition of the majority of patients' families; those who have directly practice medical examination and treatment with many professional risks; there are health workers who are willing to donate their blood to help the patient, to share the material difficulties of the person, etc. Good medical staff is not only well specialized but also have good virtue. Therefore, many of them have been active in close contact, listening and awakening in the patients' minds so that they can be assured of their treatment.

\subsection{In Relation to Colleagues}

In co-worker relationship, sometimes there is a phenomenon of disunity, but overall health staff in general and in each unit in particular are aware of their responsibilities with work, have built a relationship of solidarity, mutual assistance. The relationship of solidarity, mutual assistance comes from the sense of responsibility, from the human nature of the profession as well as from the conscience, principles of practicing medical staff rather than material benefits. Co-working relationship of medical staff manifests itself in courtesy, humility, respect for colleagues, equality in the treatment of others; irrespective of the position of work between men and women, respecting the working position of each individual; the encouragement, sharing of material difficulties, mutual encouragement in the work as well as in everyday life.

\subsection{In Relation to Science}

Professional occupations in the medical profession require medical practitioners to actively learn and practice ethics. The reason is if they stop striving they will be left behind, will not meet the requirements of health care of the people. Therefore, the medical staff has overcome the difficulties in personal life, work responsibilities of the unit, hard work and more conscious in the training of virtue and qualification. There are now 75567 doctors (including doctors, masters) (56 661 doctors in 2009), 22230 pharmacists (including doctors and masters) (19,083 pharmacists in 2009), 1736 public health staff (including doctorate, masters, public health bachelor's degree) (2009: 1,510 public health staff), 54466 physicians (55 999 physicians in 2009), 10786 college nurses, 18170 medical technicians, 59393 vocational pharmacists and pharmacy technicians, 86640 college and vocational nurses, etc. The number of doctors per 10000 people has increased over the years and in 2010 is 7.2 to 20158 (achieve the set target) (Ministry of Health, 2017) and tens of thousands of others are also constantly striving for expertise, especially in-depth techniques. All of the above numbers on the medical staff's education level cannot be obtained solely by considering the economic benefits of the individual but also from their love, conscience, responsibility for the community, for the society.

In the past years, science and technology in the field of medicine and pharmacy in Vietnam has continued to achieve remarkable success at the national and international level. The technology of producing vaccines in the country has met $10 / 11$ vaccines used in the National Extension Program, new vaccines continue to be researched and competing imported ones. Transplant technology continues to be successful with pancreas-kidney transplants, contributing along with achievements in cardiac transplantation, liver, kidney, cornea, marrow, etc. have brought transplant technology to perform in 3 regions. Applied technologies in the field of medicine focus on the study of genes, initial research on stem cell application, molecular biotechnology applications have contributed to fast and accurate identification of hand-foot-mouth disease, measles, influenza, etc. serve well for the effective diagnosis and treatment of dangerous diseases. A number of new and modern pharmaceutical technologies have been applied in the pharmaceutical industry (Yhocvn, 2018).

The achievements of above scientific research not only come from professional duties of health workers but it also include factors such as love for the profession, a passion for creativity, exploration, and learning, the basic motivation for those who do research work 


\subsection{In Relation to "Myself"}

Derived from a professional conscience, the medical team is aware of his noble mission in society. It is resolved to save people at all costs, in all circumstances, in the resistance as well as in peace, building the country. All of the Vietnamese health workers have the necessary qualities, in particular:

First, persistence: In the medical examination and treatment, the medical staff have trained themselves for the persistence and patient, listening talks of the sick person with heart, sympathy on difficulties and suffering of the patient. At the same time, not only bases on the facts that the patient informs, but also observe the patient's behavior, the appearance of the patient and the gestures, manner, manner of behavior, etc. to have a complete idea about the patient. On the other hand, this virtue also helps to dispel the suspicious, distrustful, or distrustful reactions of the patient.

Second, honesty: The honesty of the medical staff in the past time is shown quite clearly in the diagnosis, treatment; clearly informed the patient's disease and treatment direction; don't prescribe costly medicine in prescription, which do not fit budget of the patient, do not make dirty agreement between doctors and pharmacists to earn money inhumanly. However, in some cases medical staff who treat patients directly have the right to lie, if the lie is necessary to encourage the patient's spirit so that they can be assured of treatment.

In scientific research, the honesty of the medical staff demonstrates honesty in non-deceptive research results. In a peer-to-peer relationship, there is a sense of self-perception, if there are mistakes, no blame on colleagues, must be frank, sincere to help colleagues to progress together.

Honesty is considered to be a medicine that helps health workers to immunize against unethical behaviors such as corruption, bribery, low self-esteem and professional honor to achieve other personal goals.

Third, bravery: Right from the moment of entering the medical profession, Vietnamese medical staff has determined the choice of medicine is the choice of courage. Courage to accept and to sacrifice, because medical studying means youth is devoted and faces up with strong pressure of the profession. Thus, medical workers have created a love of work that is big enough for altruism. They accept life without good sleep, lack of warm meals at home and face many occupational risks. The irritability, even agitation of the patient, the moments of lack of self-control of the sick person can cause injury to health staff. Risks in scientific research can happen but they still strive to complete assigned tasks.

The bravery of the medical staff shows, in many cases, many people are willing to overcome the daily rules because of the urgency of time to save every minute, seconds to save the patient life. They know that if they fail, they may be sued by the patient's family.

Courage makes them willing to go anywhere, do whatever the country needs. Courage also shows the hard work, dare to think, dare to do, dare to take responsibility to bring the highest efficiency in the work. Their courage has made them stricter with themselves, training themselves a strong spirit, abundant health, overcome difficulties in all circumstances.

\subsection{In Relation to Society}

With the civic responsibility and the human nature of the medical profession, more and more health workers are actively involved in social movements. The team of young doctors provides free medical care for the poor in remote areas. Some hospital trade unions have lobbied their members monthly to donate money to poor patients. Deep concerning about pain and difficulties of patient's families, many humanitarian organizations who accompany the sick founded by physicians have contributed to the livelihoods of thousands of patients. The life of the medical staff is not high level, most of them are average and under, but the spirit of sharing with people who are suffering from natural disasters, still illuminated in them.

Thanks to untiring efforts of the health staff and with the determination and high responsibility in the past time, with over 441.46 (Yhocvn, 2018) thousand health workers at all levels have completed their task is to take on a great deal of work from management, preventive medicine, food hygiene and safety, drug production, population planning and family planning, to direct examination and treatment for people, the number of inpatient and outpatients, the number of days of inpatient and outpatient treatment, number of surgeries and surgical procedures annually increased by $15-20 \%$ compared to previously (in 2015, the health sector has examined more than 211.7 million patients, inpatient treatment for more than 14.46 million patients, surgery for more than 2.76 million patients) (Ministry of Health, 2017). All the achievements of the health sector cannot be denied, and the result is not possible without the leadership, management of the industry, professional effort and ethical training in the past years to make Vietnam become a bright spot for the United Nations Millennium Development Goals (MDGs) and has made Vietnam a bright spot on the world medical map. 
However, under the negative effects of the market economy, whether wants or not, besides the positive side there are still negative effects on the practice of medical ethics arising in a section of health workers. A part of the health worker has stick to material benefits in professional activity. Improper money has entered into the relationship between the physician and the patient, distorting the relationships between individuals in society and as the greater the power of money, the stronger it's to sabotage the moral relation between man and man. Expressing a sense negligence, lack of responsibility; improper communication attitude, discriminatory attitude towards each patient; unreasonably prescription, expensive prescription, shake hand with private pharmacies to receive commissions; the phenomenon of receiving "envelope" is not rare, etc. According to a survey of Hanoi Medical University: interviewed 704 doctors in hospitals, medical universities, and $65.3 \%$ responds that "sometimes" there is a sign of a violation of ethics. Of these, doctors at the central level were $68.2 \%$; provincial level is $73.6 \%$. The number of doctors shows "regular" violations of ethics in which the central level accounts for $7.0 \%$, the provincial level $6.7 \%$ and the district level $3.0 \%$. According to the study, these ethical offenses are primarily responsible for confusing patients, suggesting and receiving money $(40.5 \%)$. In addition, $39.9 \%$ of doctors prescribed drugs expensive to receive a percentage (\%) of the commission of the pharmacist, brace or transfer patients to private clinics, etc. (Lien Chau, 2009). All these images can cause people bad impressions, unfriendly views on health staff, although they are only minorities.

The causes of the above mentioned limitations and negative effects must first be objectively assessed as negatively in the general degradation of social morality. Vietnam is in a transitional period, a time of struggle between new and old, progress and backwardness, positive and negative. Thus, the negativity of the market economy is daily, hourly impact on the attitude, psychology, consciousness of the medical staff. If they do not have a political background, a strong moral foundation will be very difficult to be immune to the social diseases that are affecting them. On the other hand, the main cause is that a part of health workers themselves do not train themselves, cultivate moral qualities, do not accept the teaching and education of families, schools and society; there is a small body of medical staff who do not understand the purpose of their practice, have not dealt well with the relationship between the patient's life and their own interests. In addition, the management of the health sector has many weaknesses and the treatment regime for health workers is still inadequate, resulting in negative health effects. However, the number of staff whose mortal deterioration is not much, so we cannot because of some "worm" and misjudged the big contribution of most of health staff of Vietnam nowadays.

\section{Some Solutions to Improve the Morality of Health Workers in Our Country in Coming Time}

\subsection{Continue to Innovate the Financial Health Mechanism}

Continue to study the reform of financial mechanism in the health sector. To renovate the State budget allocation mechanism, avoiding the average, spreading situation as currently. Careful consideration should be given to methods of payment for medical services (capitation, case-control). Ensuring minimum required technical services are provided to insured person or specialized services as required for persons with economic conditions in order to ensure equality between target groups; Implementation of hospital autonomy policy. "Consistently implement the market price mechanism; o ensure the accuracy, adequacy and publicity and transparency of essential commodity price constituents and public services. Do not integrate social policies into the price of goods or services. Transfer from the allocation mechanism to the ordering mechanism; From support to service providers to direct support to beneficiaries" (The Communist Party of Vietnam, 2017). Develop a health service pricing framework based on correctness, adequacy of input costs and a transparent payment mechanism for health services. "Renovating the financial mechanism, adjusting prices of medical services according to the roadmap, correctness, adequacy and ensuring publicity, transparency ..." (The Communist Party of Vietnam, 2016) ."To step by step transfer regular expenditures from the state budget, which are directly allocated to medical examination and treatment units to support health insurance participants, which are linked to the roadmap of proper calculation and full calculation of medical service charges." (The Communist Party of Vietnam, 2018). Properly implement correct and adequate calculation of medical services in line with service quality will generate the necessary financial resources to generate stable incomes, commensurate with the intellectual work of health care workers. When income is comparable to average income of workers in society, it will create trust in the work and dedication to the purpose and professional guidelines they pursue.

\subsection{Renovate the Treatment Policy for Health Workers}

In order to improve the efficiency and quality of work, to build ethical values for medical staff, it is necessary to have a material and spiritual compensation for this team. Adequate compensation is attached with the value of labor force of health workers in work activities rather than incentives without fully calculating the position and quality of work. Good compensation policy will motivate them to fulfill their assigned tasks; stimulating creativity, 
concern for work, with the patient from which enhance the sense of responsibility in the work, moral training in the current innovation.

Adequate compensation policy (compensation is attached with specific labor value and the contribution of health workers) will contribute to the prevention of negative phenomenon, "envelope" in a section of medical staff which erodes people's love for them. One of the causes of this type of corruption is the low income, unequal treatment of health workers with other civil servants and the medical field itself. At present, in many cases, the attractiveness of civil servants in general is not due to wage income, but rather to the loophole of policy, the management mechanism to harass, to accept bribes, illegal earning.

\subsection{To Improve the Self-Discipline of Health Workers in the Current Market Economy}

In order to become a medical staff "bright medical ethics, strong medical expertise," health care workers must attach educational process of the organization with the process of self-education. Only self-education can transforms the self-esteem of the ethical values of education into their personal ethics. It is a process of organic unity. Morality in every human being is not natural, but it is the result of the whole process of striving, practicing extremely difficult. Along with the educational process is the process of self-education, the process of self-education is a process of self-mobilization, requires a strong will, a will and determination to win yourself. Without frequent self-training, moral ethics self-improvement, the medical staff is very easy to fall before the temptation of money and arise enjoying psychology.

Medical profession is a noble profession, is honored by society, medical staff must constantly learn to improve professional qualifications, moral training to fulfill the tasks assigned by the Party and the State. In current socialist-oriented market economy in Vietnam, every health worker needs to study the application of medical ethics in their working positions in order to facilitate the successful completion of the task. It is the expression of responsibility for the profession, with people as saying of President Ho Chi Minh "Good doctor as good mother".

\section{References}

Chau, L. (2009). Medical ethics Investigation. Retrieved from http://thanhnien.vn/thoi-su/dieu-tra-ve-y-duc-421329.html

Ministry of Health (2017), Health Statistics Yearbook 2015, Medical Publishing House, Hanoi, p.66, 67,113.

The Communist Party of Vietnam. (2016). Documents of the 12th National Party Congress, Publishing House. National Politics, Hanoi, p.302.

The Communist Party of Vietnam. (2017). Resolution No. 11-NQ / TW of the Party Central Committee, term XII on perfecting the socialist-oriented market economy.

The Communist Party of Vietnam. (2018). Resolution No.20-NQ / TW of the Central Party Committee for the XIIth Party Congress on enhancing the protection, care and improvement of the people's health in the new situation.

Yhocvn. (2018), Outstanding achievements of Vietnam's medicine after 63 years of development. Retrieved from https://yhocvn.net/nhung-thanh-tuu-noi-bat-cua-nganh-y -te-viet-nam-after-63-nam-truong-thanh.html

\section{Copyrights}

Copyright for this article is retained by the author(s), with first publication rights granted to the journal.

This is an open-access article distributed under the terms and conditions of the Creative Commons Attribution license (http://creativecommons.org/licenses/by/4.0/). 